UDK 528.14

\title{
GPS VIRTUALIOSIOS REFERENCINĖS STOTIES REGRESINIS PROGNOZINIS MODELIS, TAIKANT KOLOKACIJOS METODA
}

\author{
Jonas Skeivalas \\ Geodezijos ir kadastro katedra, Vilniaus Gedimino technikos universitetas, \\ Sauletekio al. 11, LT-10223 Vilnius, Lietuva \\ El.paštas Jonas.Skeivalas@ap.vtu.lt
}

Iteikta 20061107, priimta 20061221

\begin{abstract}
Santrauka. Straipsnyje pateikiamas GPS metodu nustatytų taškų koordinačių, nešlio fazių skirtumų bei pseudoatstumu pataisų skaičiavimo principas, sudarant GPS virtualiujų stočių regresinius modelius, taikant kolokacijos metodą. Regresinių lygčių parametrų reikšmès, taikant kolokacijos metodą, apskaičiuojamos mažiausiujų kvadratų metodu remiantis žinomomis tiksliomis referencinių stočių koordinatemis bei išmatuotomis atitinkamų GPS dydžių reikšmèmis. GPS vartotojo imtuvo koordinačių bei nešlio fazių skirtumų ir pseudoatstumų pataisos nustatomos pagal sudarytus prognozinius modelius. Prognozinių modelių tikslumas ịvertinamas kovariacijų matricomis.
\end{abstract}

Reikšminiai žodžiai: GPS referencinès stotys, regresija, kovariacija, prognozè.

\section{Ivadas}

Tam tikro skaičiaus GPS referencinių stočiu matavimų duomenys apibendrinami ir sisteminami virtualiosiose referencinèse stotyse, taikant atitinkama modeli [1-11]. Taip patikimiau ir tiksliau nustatoma GPS signalų vartotoju padétis, priimant jau apdorotus ir tam tikro modelio pavidalu iš virtualiujų stočių transliuojamus signalus.

Straipsnyje siūlomas regresinis virtualiujuc GPS stočių vartotojo imtuvo pataisų prognozavimo modelis, jo parametrų reikšmes nustatant mažiausiujų kvadratų bei kolokacijos metodais. Tam panaudojamos GPS referencinių stočių koordinačių pataisos ir nešlio fazių skirtumų bei pseudoatstumų pataisos. Analizuojamas pataisų modelių tikslumas.

\section{GPS virtualiosios referencinès stoties regresinio} modelio teorinis principas

Troposferos ir jonosferos itakai GPS matavimu rezultatams efektyviau eliminuoti yra sudaromos GPS virtualiosios stotys. Vartotojo padèties koordinačių pataisos arba pseudoatstumų bei nešlio fazių pataisos priklauso nuo atstumo tarp vartotojo ir virtualiosios stoties bei krypties į šią stoti $[1,2]$.

Kadangi GPS referencinès stotys ịrengiamos taškuose, kurių koordinatès tiksliai žinomos (su keleto milimetru ar centimetru klaidomis), tai kiekviena GPS referencinè stotis pagal priimtus DŽP (dirbtinių Žemès palydovų) kodinius ir nešlio signalus gali apskaičiuoti išmatuotų koordinačių, pseudoatstumų bei nešlio fazių skirtumų pataisas. Taigi galime parašyti:

$$
\begin{aligned}
& \delta \boldsymbol{T}_{\boldsymbol{i}}=\tilde{\boldsymbol{T}}_{\boldsymbol{i}}-\boldsymbol{T}_{\boldsymbol{i}} \\
& \delta \Phi_{i}^{k}(t)=\tilde{\Phi}_{i}^{k}(t)-\Phi_{i}^{k}(t), \\
& \delta R_{i}^{k}(t)=\tilde{R}_{i}^{k}(t)-R_{i}^{k}(t),
\end{aligned}
$$

čia $\delta \boldsymbol{T}_{i} \rightarrow\left(\delta X_{i}, \delta Y_{i}, \delta Z_{i}\right)^{T}-i$-osios referencinès stoties koordinačių pataisu vektorius; $T_{i} \rightarrow\left(X_{i}, Y_{i}, Z_{i}\right)^{T}-$ išmatuotų apytikrių koordinačių vektorius; $\tilde{T}_{i} \rightarrow\left(\tilde{X}_{i}, \tilde{Y}_{i}, \tilde{Z}_{i}\right)^{T}-$ tikslių koordinačių vektorius; $\delta \Phi_{i}^{k}(t)-i$-osios referencinès stoties nešlio fazių pataisa ciklais laiko momentu $t$, kai priiminèjami $k$-ojo palydovo signalai; $\quad \delta R_{i}^{k}(t)-i$-osios referencinès stoties pseudoatstumu pataisa laiko momentu $t$, kai priimami $k$ ojo palydovo signalai; $\Phi_{i}^{k}(t), \quad \tilde{\Phi}_{i}^{k}(t), \quad R_{i}^{k}(t), \quad \tilde{R}_{i}^{k}(t)-$ išmatavus gautos ir tikslios atitinkamų dydžių reikšmès.

GPS vartotojas tikslias savo $A$ taško koordinates apskaičiuoja pagal išmatuotus atitinkamus dydžius, t. y. koordinates, nešlio fazių skirtumus arba pseudoatstumus ir taikydamas GPS referencinių stočių transliuojamas šių dydžių pataisas GPS virtualiosios stoties duomenų pavidalu.

GPS virtualiosios stoties regresiniai modeliai sudaromi tiesinių parametrinių lygčių sistemos pavidalu, taikant kolokacijos metodą:

$$
\left.\begin{array}{c}
\tilde{\boldsymbol{\delta}}=\boldsymbol{A}_{\boldsymbol{u}} \boldsymbol{\tau}_{\boldsymbol{u}}+\boldsymbol{A}_{\boldsymbol{e}} \boldsymbol{\tau}_{\boldsymbol{e}} \\
\tilde{\boldsymbol{H}}_{\boldsymbol{e}}=\boldsymbol{H}_{\boldsymbol{e}}+\boldsymbol{\tau}_{\boldsymbol{e}}
\end{array}\right\},
$$


čia $\quad \delta \tilde{\boldsymbol{F}} \rightarrow \boldsymbol{\delta} \tilde{\boldsymbol{T}}, \boldsymbol{\delta} \tilde{\boldsymbol{\Phi}}(t), \delta \tilde{\boldsymbol{R}}(t)$ - atitinkamai referenciniu stočių išlygintuju koordinačių pataisų arba nešlio fazių skirtumų pataisu ar pseudoatstumų pataisų vektoriai, $\boldsymbol{A}_{\boldsymbol{u}}-$ parametrinių lygčių koordinatinių koeficientu matrica, $\quad A_{e}-$ parametrinių lygčių elipsoidinių koeficientu matrica, $\tau=\left(\tau_{u}, \tau_{e}\right)^{T}=\left(t_{1}, t_{2} \ldots t_{k}\right)^{T}-$ determinuotujų parametrų reikšmių vektorius; $\boldsymbol{H}_{\boldsymbol{e}}, \tilde{\boldsymbol{H}}_{\boldsymbol{e}}-$ atitinkamai referenciniu stočiu išmatuotu ir išlygintu elipsoidiniu aukščiu vektoriai; $k=k_{u}+k_{e}$ - bendras $\tau_{u_{i}}$ ir $\tau_{e_{i}}$ parametru skaičius, $k_{u}$ - koordinatiniu parametru $\tau_{u_{i}}$ skaičius, $k_{e}$-elipsoidiniu parametru $\tau_{e_{i}}$ skaičius.

Taigi sudaromos trys parametriniu lygčiu sistemos: pagal referenciniu stočių koordinačiu pataisas, nešlio fazių skirtumų pataisas bei pseudoatstumų pataisas.

Parametriniu lygčių sistemą (4) skaičiavimu apimčiai sumažinti parašome pataisų lygčiu sistemos pavidalu:

$$
\left.\begin{array}{l}
V_{u}=A_{u} \tau_{x}+A_{e} \tau_{e}-\delta \boldsymbol{F} \\
V_{e}=\tau_{e}
\end{array}\right\},
$$

čia $\boldsymbol{V}_{\boldsymbol{u}}=\delta \tilde{\boldsymbol{F}}-\delta \boldsymbol{F}, \quad \boldsymbol{V}_{\boldsymbol{e}}=\tilde{\boldsymbol{H}}_{\boldsymbol{e}}-\boldsymbol{H}_{\boldsymbol{e}}-$ atitinkami pataisu vektoriai, $\delta \boldsymbol{F} \rightarrow \boldsymbol{\delta} \boldsymbol{T}, \boldsymbol{\delta} \Phi(t), \boldsymbol{\delta} \boldsymbol{R}(\boldsymbol{t})$ - referencinèse stotyse nustatytų atitinkamų dydžių pataisų vektoriai, $n=n_{u}+r$ - bendras pataisų lygčiu skaičius, $n_{u}-$ koordinatinių lygčiu skaičius, $r$ - elipsoidinių lygčiu skaičius.

Sistema (5) blokinių matricų pavidalu:

$$
\boldsymbol{V}=\left(\begin{array}{cc}
\boldsymbol{A}_{u} & \boldsymbol{A}_{\boldsymbol{e}} \\
0 & \boldsymbol{E}
\end{array}\right)\left(\begin{array}{c}
\tau_{u} \\
\tau_{e}
\end{array}\right)-\left(\begin{array}{c}
\delta \boldsymbol{F} \\
0
\end{array}\right)=\boldsymbol{A} \tau-\delta \boldsymbol{F}_{0},
$$

čia $V=\left(V_{u} V_{e}\right)^{T}, E$ - vienetinè matrica, $A=\left(\begin{array}{cc}A_{u} & A_{e} \\ 0 & E\end{array}\right)$, $\delta \boldsymbol{F}_{0}=\left(\begin{array}{c}\boldsymbol{\delta} \boldsymbol{F} \\ 0\end{array}\right)$.

Parametriniu lygčiu koeficientu matricai $\boldsymbol{A}_{\boldsymbol{u}}$ sudaryti taikomos redukuotosios apytikrès referenciniu stočių koordinatès. Matricai $\boldsymbol{A}_{\boldsymbol{e}}$ sudaryti taikomi redukuotieji referencinių stočių elipsoidiniai aukščiai. Taikant koordinačių pataisų arba nešlio faziu pataisų ar pseudoatstumu pataisų modelius matricų $\boldsymbol{A}_{\boldsymbol{u}}$ išraiškos yra skirtingos.

Pataisų lygčių sistema (6) sprendžiama mažiausiujų kvadratų metodu, ir gaunamas parametrų reikšmiu vektorius:

$$
\tau=N^{-1} A^{T} P \delta F,
$$

čia $\boldsymbol{N}=\boldsymbol{A}^{T} \boldsymbol{P A}-$ normalinių lygčiu koeficientu matrica, $\boldsymbol{P}=\left(\boldsymbol{P}_{u} \boldsymbol{P}_{\boldsymbol{e}}\right)_{\text {diag }}-$ referenciniu stočiu atitinkamu dydžiu pataisų $\delta F_{i}$ ir elipsoidiniu aukščių $H_{e_{i}}$ svorių matrica.
Normalinių lygčiu koeficientų matricą $N$ galima užrašyti blokiniu pavidalu:

$$
\begin{aligned}
& N=\left(\begin{array}{cc}
A_{u} & A_{e} \\
0 & E
\end{array}\right)^{T}\left(\begin{array}{ll}
P_{u} & \\
& P_{e}
\end{array}\right)\left(\begin{array}{cc}
A_{u} & A_{e} \\
0 & E
\end{array}\right)= \\
& \left(\begin{array}{cc}
A_{u}^{T} P_{u} A_{u} & A_{u}^{T} P_{u} A_{e} \\
A_{e}^{T} P_{u} A_{u} & A_{e}^{T} P_{u} A_{e}+P_{e}
\end{array}\right)=\left(\begin{array}{cc}
N_{11} & N_{12} \\
N_{21} & N_{22}
\end{array}\right) .
\end{aligned}
$$

Apskaičiuotų parametrų reikšmių vektoriaus $\tau$ tikslumas įvertinamas jų kovariacijų matrica $\boldsymbol{K}_{\tau}$ :

$$
\boldsymbol{K}_{\tau}=\sigma_{0}^{2} \boldsymbol{N}^{-1}=\sigma_{0}^{2}\left(\begin{array}{ll}
\boldsymbol{Q}_{11} & \boldsymbol{Q}_{12} \\
\boldsymbol{Q}_{21} & \boldsymbol{Q}_{22}
\end{array}\right),
$$

čia $\sigma_{0}-$ matavimo rezultato, kurio svoris lygus vienetui, standartinis nuokrypis.

Standartinio nuokrypio įvertis $m_{0}$ nustatomas iš formulès

$$
\sigma_{0}^{2} \approx m_{0}^{2} \approx \frac{1}{n-k} \boldsymbol{V}^{\boldsymbol{T}} \boldsymbol{P} \boldsymbol{V} .
$$

Parametrų vektoriaus $\tau$ blokiniu dalių $\tau_{u}$ ir $\tau_{e}$ kovariacijų matricos $\boldsymbol{K}_{\tau_{u}}$ ir $\boldsymbol{K}_{\tau_{e}}$ gaunamos iš išraiškos (9):

$$
\begin{aligned}
& \boldsymbol{K}_{\tau_{u}}=\sigma_{0}^{2} \boldsymbol{Q}_{11}, \\
& \boldsymbol{K}_{\tau_{\boldsymbol{e}}}=\sigma_{0}^{2} \boldsymbol{Q}_{22} .
\end{aligned}
$$

Blokinių vektoriu $\tau_{u}$ ir $\tau_{e}$ tarpusavio kovariaciju matricos yra lygios:

$$
\boldsymbol{K}\left(\begin{array}{l}
\boldsymbol{\tau}_{u} \\
\boldsymbol{\tau}_{\boldsymbol{e}}
\end{array}\right)=\sigma_{0}^{2} \boldsymbol{Q}_{12}
$$

Išlygintujų parametrų vektoriaus $\delta \tilde{F}=\left(A_{u} A_{e}\right) \tau$ (formulès (4) pirmoji lygtis) kovariacijų matrica $\boldsymbol{K}_{\delta \tilde{\boldsymbol{F}}}$ yra lygi

$$
\begin{aligned}
& K_{\delta \tilde{F}}=\left(A_{u} A_{e}\right) K_{\tau}\left(A_{u} A_{e}\right)^{T}=\sigma_{0}^{2}\left(A_{u} Q_{11} A_{u}^{T}+\right. \\
& \left.A_{e} Q_{21} A_{u}^{T}+A_{u} Q_{12} A_{e}^{T}+A_{e} Q_{22} A_{e}^{T}\right) .
\end{aligned}
$$

Ivertinsime kolokacijos metodo itaką nustatomu regresijos modelio parametru tikslumui. Tam taikysime blokini atvirkštinès matricos $N^{-1}$ pavidalą pagal K. R. Koch [4]:

$$
\begin{aligned}
& \boldsymbol{N}^{-1}=\left(\begin{array}{ll}
\boldsymbol{N}_{11} & \boldsymbol{N}_{12} \\
\boldsymbol{N}_{21} & \boldsymbol{N}_{22}
\end{array}\right)^{-1}= \\
& \left(\begin{array}{c|c}
\boldsymbol{N}_{11}^{-1}+\boldsymbol{F H}^{-1} \boldsymbol{F}^{\boldsymbol{T}} & -\boldsymbol{F} \boldsymbol{H}^{-1} \\
-\boldsymbol{H}^{-1} \boldsymbol{F}^{\boldsymbol{T}} & \boldsymbol{H}^{-1}
\end{array}\right),
\end{aligned}
$$

čia $F=N_{11}^{-1} N_{12}, H=N_{22}-N_{21} N_{11}^{-1} N_{12}$. 
Formulès (9) ir (15) rodo, kad matricos $\boldsymbol{Q}_{11}$ diagonalieji nariai yra didesni už matricos $N_{11}^{-1}$ diagonaliuosius narius, t. y.

$$
\left(\boldsymbol{Q}_{11}\right)_{i i}=\left(\boldsymbol{N}_{11}^{-1}+\boldsymbol{F} \boldsymbol{H}^{-1} \boldsymbol{F}^{\boldsymbol{T}}\right)_{i i}>\left(\boldsymbol{N}_{11}^{-1}\right)_{i i}
$$

nes kovariaciju matricos diagonalieji nariai visada yra teigiamieji.

Apskaičiuotujų parametrų vektoriaus $\tau=\left(\tau_{u} \tau_{e}\right)^{T}$ kovariaciju matricos $\boldsymbol{K}_{\tau}$ blokinè dalis $\boldsymbol{K}_{\tau_{u}}=\sigma_{0}^{2} \boldsymbol{Q}_{11}$ apibūdina parametrų vektoriaus $\tau_{\boldsymbol{u}}$ tikslumą, gaunamą netaikant kolokacijos metodo, t. y. $\quad \boldsymbol{K}_{\tau_{u}}^{\prime}=\sigma_{0}^{2} \boldsymbol{N}_{11}^{-1}$. Formule (16) rodo, kad parametru vektoriaus $\tau_{u}$ tikslumas yra mažesnis, kai taikomas kolokacijos metodas, nes kovariaciju matricos $\boldsymbol{K}_{\tau_{u}}$ diagonalieji nariai (dispersijos) yra didesni už kovariacijų matricos $\boldsymbol{K}_{\tau_{u}}^{\prime}$ diagonaliuosius narius.

Regresinių lygčių parametrų vektorius $\tau_{\boldsymbol{u}}$, taikant kolokacijos metoda, tampa mažiau tikslus, palyginti su atveju, kai šis metodas netaikomas, nes tam tikra dalis matavimo duomenu panaudojama papildomu parametru vektoriui $\tau_{\boldsymbol{e}}$ apskaičiuoti. Nepaisant šių tikslumo prasme tam tikru nuostolių, taikant papildomuc parametru vektoriuc $\tau_{\boldsymbol{e}}$ galima patikimiau konstruoti prognozini GPS vartotojo imtuvo koordinačių tikslinimo modeli.

GPS virtualiosios referencinès stoties regresinio modelio parametrų reikšmių vektorius $\tau$ naudojamas sudarant GPS vartotojų imtuvais nustatomų tašku koordinačių pataisų prognozinị modelį. Šio modelio išraiška:

$$
\delta \boldsymbol{F}_{s}=\boldsymbol{A}_{s} \tau_{u}
$$

čia $\delta \boldsymbol{F}_{\boldsymbol{s}}$ - nustatomu taškų koordinačių pataisų arba nešlio fazių skirtumų pataisų ar pseudoatstumų pataisu vektorius, $\boldsymbol{A}_{\boldsymbol{s}}-$ koeficientų matrica, sudaroma pagal vartotoju imtuvais nustatytas apriorines redukuotąsias taškų koordinates $\left(X_{s}^{\prime}, Y_{s}^{\prime}, Z_{s}^{\prime}\right)$.

Apskaičiuotojo vektoriaus $\boldsymbol{\delta}_{\boldsymbol{s}}$ kovariacijų matrica $\boldsymbol{K}_{\delta \boldsymbol{F}_{s}}$ yra lygi

$$
K_{\delta F_{s}}=A_{s} K_{\tau_{u}} A_{s}^{T}=\sigma_{0}^{2} A_{s} Q_{11} A_{s}^{T}
$$

GPS vartotojų imtuvų tikslių matuojamujų dydžių vektorius gaunamas taip:

$$
\tilde{T}_{s}=T_{s}+\delta F_{s}
$$

\section{GPS virtualiosios referencinès stoties modelis taikant koordinačių korektūrą}

Šiam modeliui sudaryti taikomos tiksliosios referencinių stočių koordinatès bei jų apriorinès koordinatès, nustatytos atitinkamą epochą. Pagal referencinių stočių duomenis, taikant kolokacijos metodą, sudaroma parametrinių pataisų lygčių sistema (5)

$$
\left.\begin{array}{l}
V_{u}=A_{u} \tau_{u}+A_{e} \tau_{e}-\delta \boldsymbol{T} \\
V_{e}=\tau_{e}
\end{array}\right\},
$$

čia $V_{u}=\delta \tilde{T}-\delta T, \quad V_{e}=\tilde{H}_{e}-H_{e}, \quad \delta T_{i}=\tilde{T}_{i}-T_{i}=$ $\left(\tilde{X}_{i}-X_{i}, \tilde{Y}_{i}-Y_{i}, \tilde{Z}_{i}-Z_{i}\right)^{T}$.

Taikant sąlygą $k>n$ sudaroma atitinkamos eilès regresinė lygtis. Panaudoję antrosios eilès regresinę lygti, parametrų $\tau_{i}$ skaičių turètume lygu $k=6+k_{e}$, čia $k_{e}=r-$ referencinių stočių skaičius.

Matricos $\boldsymbol{A}_{\boldsymbol{u}}$ ir $\boldsymbol{A}_{\boldsymbol{e}}$ turi blokini pavidalą:

$$
A_{u}=\left(\begin{array}{c}
A_{u_{1}} \\
\vdots \\
A_{u_{r}}
\end{array}\right), A_{e}=\left(A_{e_{1}} \ldots A_{e_{r}}\right)_{\mathrm{diag}}
$$

Blokinès dalys $\boldsymbol{A}_{\boldsymbol{u}_{\boldsymbol{i}}}$ ir $\boldsymbol{A}_{\boldsymbol{e}_{\boldsymbol{i}}}$ priklauso $i$-ajai referencinei stočiai.

Blokinès dalys $\boldsymbol{A}_{\boldsymbol{u}_{\boldsymbol{i}}}$ sudaromos panaudojus referencinių stočių redukuotąsias koordinates $\left(X_{i}^{\prime}, Y_{i}^{\prime}, Z_{i}^{\prime}\right)$ :

$$
A_{u_{i}}=\left(\begin{array}{c}
A_{x_{i}} \\
A_{y_{i}} \\
A_{z_{i}}
\end{array}\right)=\left(\begin{array}{cccccc}
X_{i}^{\prime} & Y_{i}^{\prime} & Z_{i}^{\prime} & X_{i}^{\prime 2} & 0 & 0 \\
X_{i}^{\prime} & Y_{i}^{\prime} & Z_{i}^{\prime} & 0 & Y_{i}^{\prime 2} & 0 \\
X_{i}^{\prime} & Y_{i}^{\prime} & Z_{i}^{\prime} & 0 & 0 & Z_{i}^{\prime 2}
\end{array}\right)
$$

Redukuotosios referencinių stočių koordinatès gaunamos iš lygybių:

$$
\begin{aligned}
& X_{i}^{\prime}=\left(X_{i}-X_{0}\right) \cdot 10^{-5}, \\
& Y_{i}^{\prime}=\left(Y_{i}-Y_{0}\right) \cdot 10^{-5}, \\
& Z_{i}^{\prime}=\left(Z_{i}-Z_{0}\right) \cdot 10^{-5},
\end{aligned}
$$

čia $X_{0}, Y_{0}, Z_{0}-$ referencinių stočių tinklo mažiausios suapvalintos koordinačių reikšmès.

Matricos $\boldsymbol{A}_{\boldsymbol{e}}$ blokiné dalis $\boldsymbol{A}_{\boldsymbol{e}_{i}}$ yra lygi

$$
\boldsymbol{A}_{e_{i}}=\left(\begin{array}{cccccc}
0 & 0 & \ldots & H_{e_{i}}^{\prime} & \ldots & 0 \\
0 & 0 & \ldots & H_{e_{i}}^{\prime} & \ldots & 0 \\
0 & 0 & \ldots & H_{e_{i}}^{\prime} & \ldots & 0
\end{array}\right)
$$

čia $H_{e_{i}}^{\prime}=H_{e_{i}} \cdot 10^{-2}-$ redukuotasis elipsoidinis aukštis. 
Toliau parametrų vektoriaus $\tau=\left(\tau_{u} \tau_{e}\right)^{T}$ reikšmé nustatoma pagal formulę (7), o jos kovariaciju matrica $\boldsymbol{K}_{\tau}$ pagal formulę (9). GPS vartotojų imtuvų koordinačiu pataisu prognoziniam modeliui formuoti taikoma formule (15).

\section{GPS virtualiosios referencinès stoties modelis taikant nešlio fazių skirtumų bei pseudoatstumų pataisas}

Regresinio modelio nešlio fazių skirtumų ir pseudoatstumų parametrinių pataisų lygčių sistemos užrašomos taikant išraišką (5):

$$
\left.\begin{array}{l}
\boldsymbol{V}_{\varphi}=\boldsymbol{A}_{\varphi} \tau_{\varphi}+\boldsymbol{A}_{\boldsymbol{e}} \tau_{\boldsymbol{e}}-\delta \Phi \\
\boldsymbol{V}_{\boldsymbol{e}}=\tau_{\boldsymbol{e}}
\end{array}\right\}
$$

ir

$$
\left.\begin{array}{l}
V_{R}=A_{R} \tau_{R}+A_{e} \tau_{e}-\delta R \\
V_{e}=\tau_{e}
\end{array}\right\}
$$

čia $\delta \Phi, \delta \boldsymbol{R}$ - atitinkamai nešlio fazių skirtumų ir pseudoatstumų pataisu vektoriai.

Matricos $\boldsymbol{A}_{\varphi}$ ir $\boldsymbol{A}_{\boldsymbol{R}}$ turi blokini pavidalą:

$$
A_{\varphi}=A_{R}=\left(A_{\varphi_{1}} A_{\varphi_{2}} \ldots A_{\varphi_{r}}\right)^{T} \text {. Blokinès dalys } A_{\varphi_{i}}
$$

yra vienodos nustatant nešlio fazių skirtumų ar pseudoatstumu pataisas, t. y. $\boldsymbol{A}_{\boldsymbol{\varphi}_{i}}=\boldsymbol{A}_{\boldsymbol{R}_{i}}$. Blokinès dalys $\boldsymbol{A}_{\boldsymbol{\varphi}_{i}}$ ir $\boldsymbol{A}_{\boldsymbol{R}_{i}}$ taikant antrosios eilès regresinę išraišką:

$$
\boldsymbol{A}_{\varphi_{i}}=A_{\boldsymbol{R}_{i}}=\left(X_{i}^{\prime} Y_{i}^{\prime} Z_{i}^{\prime} X_{i}^{2} Y_{i}^{2} Z_{i}^{2}\right)
$$

Referencinių stočių redukuotosios koordinatės $\left(X_{i}^{\prime} Y_{i}^{\prime} Z_{i}^{\prime}\right)$ skaičiuojamos pagal anksčiau aprašytas formules. Matricos $\boldsymbol{A}_{\boldsymbol{e}_{i}}$ turi anksčiau aprašytas išraiškas.

Parametrų vektoriaus $\tau=\left(\tau_{\varphi} \tau_{e}\right)^{T}$, taikant nešlio fazių skirtumus, bei vektoriaus $\tau^{\prime}=\left(\varphi_{R} \tau_{e}\right)^{T}$, taikant pseudoatstumus, reikšmès skaičiuojamos pagal formulę (7). Vektorių $\tau$ ir $\tau^{\prime}$ tikslumas ivertinamas ju kovariaciju matricomis $\boldsymbol{K}_{\tau}$ ir $\boldsymbol{K}_{\tau^{\prime}}$, kurios skaičiuojamos pagal formulę (9). GPS vartotojų imtuvų nešlio fazių skirtumuc bei pseudoatstumų pataisų prognoziniai modeliai sudaromi taikant formulę (15).

\section{Išvados}

1. GPS virtualiosios referencinès stoties regresiniu lygčių parametrų reikšmėms nustatyti pasiūlyta taikyti kolokacijos metodą. Šiuo atveju padaugeja skaičiavimuose naudojamų duomenu bei parametrų, palyginti nei paprasto regresinio modelio atveju, išliekant tos pačios eilès regresinėms lygtims.
2. Regresinio modelio parametrų vektoriaus $\tau_{u}$, taikant kolokacijos metodą, yra mažiau tikslus nei tuo atveju, kai šis metodas netaikomas. Taip atsitinka dèl papildomu parametrų vektoriaus $\tau_{\boldsymbol{e}}$ i̇vedimo skaičiavimų procedūrose. Tačiau taikant kolokacijos metodą galima patikimiau formuoti prognozini GPS vartotojo imtuvo koordinačių tikslinimo modelį.

\section{Literatūra}

1. WANNINGER, L. Virtuelle GPS-Referenzstationen für grossräumige kinematische Anwendungen. Zeitschrift für Vermessungswesen, No 3. Stuttgart: Verlag K. Witwer, 2003, S. 196-202.

2. HANKEMEIER, P. Der Satellitenpositionierungsdienst SAPOS in Deutschland. In Multifunktionale GNSSReferenzstationsysteme für Europa. Workshop von 4-5. März 2002 in der Europäischen Akademie für städtische Umwelt. Berlin, 2002, S. 16-23.

3. TEUNISSEN, P. J. G. The parameter distributions of the integer GPS model. Journal of Geodesy, No 1 (76), 2002, p. 41-48.

4. KOCH, K. R. Einführung in die Bayes-Statistik. SpringerVerlag, Berlin Heidelberg, 2000. 225 S.

5. SKEIVALAS, J. Accuracy determination of the coordinates augmentations of GPS vectors by measuring double phase shifts of the carrier. Geodesy and Cartography (Geodezija ir kartografija), Vol XXIX, No 4, 2003, p. 115-118 (in Lithuanian).

6. BAUER, M. Vermessung und Ortung mit Satelliten. Heidelberg: Wichmann, 1994. 274 S.

7. HOFMANN-WELLENHOF, B.; LICHTENEGGER, H. and COLLINS, J. Global Positioning System. In Theory and Practice. Wien, New York: Springer-Verlag, 1992. $326 \mathrm{p}$.

8. LEICK, A. GPS Satellite Surveying. New York, Chichester, Brisbane, Toronto, Singapore: John Wiley and Sons, 1995. $352 \mathrm{p}$.

9. MARKUZE, J. I. Algorithms for geodetic networks adjustment using computers (Алгоритмы для уравнивания геодезических сетей на ЭВМ). Moscow: Nedra, 1989. 248 p. (in Russian).

10. GAO, Y.; and LIU, Z. Z. Precise Ionosphere Modeling Using Regional GPS Network Data. Journal of Global Positioning Systems, Vol 1, No 1, 2002, p. 18-24.

11. SKEIVALAS, J. Regression model of virtual GPS reference. Geodesy and Cartography (Geodezija ir kartografija), Vol XXXII, No 4, 2006, p. 96-99 (in Lithuanian).

Jonas SKEIVALAS. Prof, Doctor Habil. Vilnius Gediminas Technical University. Dept of Geodesy and Cadastre, Sauletekio al. 11, LT-10223 Vilnius, Lithuania. $\mathrm{Ph}+37052744$ 703, Fax +370 52744 705,

e-mail: jonas.skeivalas@ap.vtu.lt.

Author of two monographs and more than 130 scientific papers. Participated in many intern conferences and research visits to the Finish Geodetic Institute.

Research interests: processing of measurements with respect to tolerances, adjustment of geodetic networks. 